\title{
Loss of $\mathrm{IP}_{3}$ Receptor-Dependent $\mathrm{Ca}^{2+}$ Increases in Hippocampal Astrocytes Does Not Affect Baseline CA1 Pyramidal Neuron Synaptic Activity
}

\author{
Jeremy Petravicz, ${ }^{1}$ Todd A. Fiacco, ${ }^{2}$ and Ken D. McCarthy ${ }^{1,2}$ \\ ${ }^{1}$ Curriculum in Neurobiology and ${ }^{2}$ Department of Pharmacology, University of North Carolina at Chapel Hill, Chapel Hill, North Carolina 27599
}

\begin{abstract}
Astrocytes in the hippocampus release calcium $\left(\mathrm{Ca}^{2+}\right)$ from intracellular stores intrinsically and in response to activation of $\mathrm{G}_{\mathrm{q}}$-linked G-protein-coupled receptors (GPCRs) through the binding of inositol 1,4,5-trisphosphate $\left(\mathrm{IP}_{3}\right)$ to its receptor (IP $\left.{ }_{3} \mathrm{R}\right)$. Astrocyte Ca ${ }^{2+}$ has been deemed necessary and sufficient to trigger the release of gliotransmitters, such as ATP and glutamate, from astrocytes to modulate neuronal activity. Several lines of evidence suggest that $\mathrm{IP}_{3} \mathrm{R}$ type $2\left(\mathrm{IP}_{3} \mathrm{R} 2\right)$ is the primary $\mathrm{IP}_{3} \mathrm{R}$ expressed by astrocytes. To determine whether $I_{3} R 2$ is the primary functional $I_{3} R$ responsible for astrocytic $\mathrm{Ca}^{2+}$ increases, we conducted experiments using an $\mathrm{IP}_{3} \mathrm{R} 2$ knock-out mouse model ( $\left.\mathrm{IP}_{3} \mathrm{R} 2 \mathrm{KO}\right)$. We show, for the first time, that lack of $\mathrm{IP}_{3} \mathrm{R} 2$ blocks both spontaneous and $\mathrm{G}_{\mathrm{q}}$-linked $\mathrm{GPCR}$ mediated increases in astrocyte $\mathrm{Ca}^{2+}$. Furthermore, neuronal $\mathrm{G}_{\mathrm{q}}$-linked $\mathrm{GPCR} \mathrm{Ca}{ }^{2+}$ increases remain intact, suggesting that $\mathrm{IP}_{3} \mathrm{R} 2$ does not play a major functional role in neuronal calcium store release or may not be expressed in neurons. Additionally, we show that lack of $\mathrm{IP}_{3} \mathrm{R} 2$ in the hippocampus does not affect baseline excitatory neuronal synaptic activity as measured by spontaneous EPSC recordings from CA1 pyramidal neurons. Whole-cell recordings of the tonic NMDA receptor-mediated current indicates that ambient glutamate levels are also unaffected in the $\mathrm{IP}_{3} \mathrm{R} 2 \mathrm{KO}$. These data show that $\mathrm{IP}_{3} \mathrm{R} 2$ is the key functional $\mathrm{IP}_{3} \mathrm{R}_{\text {driving }} \mathrm{G}_{\mathrm{q}}$-linked GPCR-mediated Ca ${ }^{2+}$ increases in hippocampal astrocytes and that removal of astrocyte $\mathrm{Ca}^{2+}$ increases does not significantly affect excitatory neuronal synaptic activity or ambient glutamate levels.
\end{abstract}

Key words: astrocyte; calcium; inositol 1,4,5-trisphosphate; $\mathrm{IP}_{3}$ receptor; hippocampus; gliotransmitter

\section{Introduction}

Astrocytes have been reported recently to have a functional role in neuronal excitability (Araque et al., 1998a; Haydon and Carmignoto, 2006), heterosynaptic depression (Pascual et al., 2005; Serrano et al., 2006; Andersson et al., 2007), cerebrovascular dynamics (Zonta et al., 2003; Straub and Nelson, 2007), and pathological states such as epilepsy (Kang et al., 2005; Tian et al., 2005; Fellin et al., 2006a). One unifying feature of these findings is that astrocyte modulation of these processes occurs via a $\mathrm{Ca}^{2+}$ dependent release of "gliotransmitters," including ATP (which is converted to adenosine by ectonucleotidases) and glutamate (Montana et al., 2006). Astrocytes primarily use spatially and temporally encoded increases in $\mathrm{Ca}^{2+}$ as an intracellular signaling mechanism (Cornell-Bell et al., 1990; Jensen and Chiu, 1990; Scemes and Giaume, 2006). Astrocytes display $\mathrm{Ca}^{2+}$ increases both spontaneously (Parri et al., 2001; Nett et al., 2002; Hirase et al., 2004) and in response to neuronal stimulation (Porter and McCarthy, 1996; Aguado et al., 2002; Perea and Araque, 2005)

Received Dec. 17, 2007; revised April 2, 2008; accepted April 6, 2008.

This work was supported by National Institutes of Health Grants NS033938 and NS020212. We thank Dr. Cendra Agulhon for considerable discussion and feedback on previous versions of this manuscript. We also thank Dr. Ju Chen (University of California, San Diego, San Diego, CA) for the mice used in this study.

Correspondence should be addressed to Jeremy Petravicz, Curriculum in Neurobiology, University of North Carolina at Chapel Hill, Campus Box \#7320, Chapel Hill, NC 27599-7320. E-mail: jeremy_petravicz@med.unc.edu.

DOI:10.1523/JNEUROSCI.5572-07.2008

Copyright $\odot 2008$ Society for Neuroscience $\quad$ 0270-6474/08/284967-07\$15.00/0 and have been reported to modulate synaptic transmission through activation of metabotropic glutamate receptors (mGluRs), ionotropic glutamate receptors (iGluRs), and adenosine receptors (Haydon and Carmignoto, 2006).

Calcium increases in astrocytes are elicited predominantly by $\mathrm{G}_{\mathrm{q}}$-linked G-protein-coupled receptor (GPCR) activation, driving the production of $\mathrm{IP}_{3}$ and the activation of $\mathrm{IP}_{3}$ receptors $\left(\mathrm{IP}_{3} \mathrm{Rs}\right.$ ) coupled to endoplasmic reticulum (ER) $\mathrm{Ca}^{2+}$ stores. $\mathrm{IP}_{3} \mathrm{Rs}$ are a family of genes expressing three isoforms (types 1-3) of an $\mathrm{ER} \mathrm{Ca}^{2+}$ release channel that are found in nearly every cell type (Foskett et al., 2007). Immunohistochemical studies aimed at identifying the expression profile of $\mathrm{IP}_{3} \mathrm{Rs}$ in the brain suggest that hippocampal astrocytes express primarily $\mathrm{IP}_{3} \mathrm{R} 2$. Evidence for $\mathrm{IP}_{3} \mathrm{R} 2$ expression in neurons is inconclusive (Sharp et al., 1999; Holtzclaw et al., 2002; Hertle and Yeckel, 2007). These data point to $\mathrm{IP}_{3} \mathrm{R} 2$ as a potential key mediator of astrocyte intracellular $\mathrm{Ca}^{2+}$ release and $\mathrm{Ca}^{2+}$-dependent signaling cascades, but functional evidence for $\mathrm{IP}_{3} \mathrm{R} 2$ in astrocytes is limited and has not been demonstrated in situ (Sheppard et al., 1997; Weerth et al., 2007).

We used an $\mathrm{IP}_{3} \mathrm{R} 2$ knock-out (KO) mouse model to determine whether $\mathrm{IP}_{3} \mathrm{R} 2$ has a functional role in $\mathrm{Ca}^{2+}$ increases of hippocampal astrocytes and neurons. We present the novel finding that genetic deletion of $\mathrm{IP}_{3} \mathrm{R} 2$ results in complete loss of spontaneous and agonist-evoked $\mathrm{IP}_{3} \mathrm{R}$-dependent $\mathrm{Ca}^{2+}$ increases in astrocytes but leaves intact agonist-evoked $\mathrm{IP}_{3} \mathrm{R}$-dependent $\mathrm{Ca}^{2+}$ 
increases in neurons. These data indicate that $\mathrm{IP}_{3} \mathrm{R} 2$ is the primary functional $\mathrm{IP}_{3} \mathrm{R}$ in astrocytes, and that $\mathrm{IP}_{3} \mathrm{R} 2$ does not play a demonstrated role in CA1 pyramidal neurons. We performed electrophysiological recordings of CA1 pyramidal neuron spontaneous EPSCs (sEPSCs) to determine the effect of eliminating astrocytic $\mathrm{Ca}^{2+}$ responses on baseline neuronal excitatory synaptic activity. No significant changes were found in any of the AMPA receptor (AMPAR) and NMDA receptor (NMDAR) sEPSC parameters of mice lacking astrocytic $\mathrm{Ca}^{2+}$ responses compared with littermate controls. Our results indicate that astrocytic $\mathrm{Ca}^{2+}$ responses are not important in modulating basal neuronal excitatory synaptic activity, contrary to the current state of the literature. We also found no differences in activation of NMDARs by ambient glutamate, providing additional evidence that ambient glutamate of glial origin is not released in a $\mathrm{Ca}^{2+}$. dependent manner (Jabaudon et al., 1999; Cavelier and Attwell, 2005). This study provides the first functional evidence that $I_{3} R 2$ is the only $I_{3} R$ isoform expressed by astrocytes, $I_{3} R 2$ is not required for neuronal $\mathrm{G}_{\mathrm{q}}$ GPCR-mediated $\mathrm{Ca}^{2+}$ elevations, and removal of astrocyte $\mathrm{Ca}^{2+}$ increases has no effect on basal neuronal excitatory activity.

\section{Materials and Methods}

Generation of $I P_{3} R 2 \mathrm{KO}$ mice. $\mathrm{IP}_{3} \mathrm{R} 2 \mathrm{KO}$ mice were generated as described previously (Li et al., 2005). Briefly, a $539 \mathrm{bp}$ fragment of exon 3 of $\mathrm{IP}_{3} \mathrm{R} 2$ (116 bp) was inserted into a targeting vector between two loxP sites. Mice were bred to heterozygosity for the floxed allele $\left(\mathrm{IP}_{3} \mathrm{R} 2{ }^{+/ \text {flox }}\right)$ and crossed to Pro-Cre mice. Pro-Cre, $\mathrm{IP}_{3} \mathrm{R} 22^{+/ \text {flox }}$ were crossed to generate germline heterozygous null mutant offspring $\left(\mathrm{IP}_{3} \mathrm{R} 2^{+/-}\right)$, which were interbred to generate homozygous full mutant mice $\left(\mathrm{IP}_{3} \mathrm{R} 2^{-1-}\right)$ and littermate controls $\left(\mathrm{IP}_{3} \mathrm{R} 2^{+/+}\right.$and $\left.\mathrm{IP}_{3} \mathrm{R} 2^{+/-}\right)$. Mice were genotyped by PCR analysis using genomic DNA with $\mathrm{IP}_{3} \mathrm{R} 2$ wild-type (WT) and mutant allelespecific primers as given in the study by Li et al. (2005).

Hippocampal slice preparation. All procedures followed the guidelines of the Institutional Animal Care and Use Committee of University of North Carolina at Chapel Hill. Littermate control and $\mathrm{IP}_{3} \mathrm{R} 2$ knock-out mice $10-16 \mathrm{~d}$ of age [postnatal day 10 (P10) to P16] were anesthetized by isoflurane inhalation. The brains were rapidly removed after decapitation and submerged into $4^{\circ} \mathrm{C}$ slicing buffer containing the following (in m) : $125 \mathrm{NaCl}, 10$ glucose, $1.25 \mathrm{NaH}_{2} \mathrm{PO}_{4}, 26 \mathrm{NaCHO}_{3}, 2.5 \mathrm{KCl}, 3.8$ $\mathrm{MgCl}_{2}$, and 0.1 kynurenic acid and bubbled with $95 \% \mathrm{O}_{2}$ and $5 \% \mathrm{CO}_{2}$. Brains were cut sagittally at a thickness of $300 \mu \mathrm{m}$ on a Leica (Bannockburn, IL) vibratome. During sectioning, brains were kept submerged in $4^{\circ} \mathrm{C}$ oxygenated slicing buffer. Hippocampi were dissected out of each brain slice and incubated $45 \mathrm{~min}$ in artificial CSF (ACSF) warmed to $35-37^{\circ} \mathrm{C}$ and bubbled continuously with $95 \% \mathrm{O}_{2}$ and $5 \% \mathrm{CO}_{2}$. The ACSF contained the following (in mM): $125 \mathrm{NaCl}, 10$ glucose, $1.25 \mathrm{NaH}_{2} \mathrm{PO}_{4}$, $26 \mathrm{NaCHO}_{3}, 2.5 \mathrm{KCl}, 2.5 \mathrm{CaCl}_{2}$, and $1.3 \mathrm{MgCl}_{2}$.

Calcium imaging. Astrocytes were bulk loaded with either the $\mathrm{Ca}^{2+}$ indicator Calcium Green-1 A.M. or Fluo-4 A.M. as described previously (Nett et al., 2002). Slices were incubated for $45 \mathrm{~min}$ at $35-37^{\circ} \mathrm{C}$ in oxygenated ACSF that included either $16 \mu \mathrm{M}$ Fluo-4 A.M. or $11 \mu \mathrm{M}$ Calcium Green $1-\mathrm{AM}$ ester dye and $0.07 \%$ pluronic acid (final DMSO concentration, $0.4 \%)$. For measuring neuronal $\mathrm{Ca}^{2+}$ increases, CA1 pyramidal neurons were patch clamped with $200 \mu \mathrm{M}$ Alexa 568 and $400 \mu \mathrm{M}$ Fluo-4 calcium indicator dye made up in neuronal internal solution (see below). The pipette was then removed, and the neuron was allowed to recover for $10 \mathrm{~min}$. Regions of interest were placed over the cell bodies of astrocytes and over the cell body and primary dendrite of CA1 pyramidal neurons. Increases in average fluorescence in regions of interest indicate an increase in $\mathrm{Ca}^{2+}$ concentration. Fold increase over baseline was calculated for each trace and reported as $\Delta F / F_{0}$.

Neuronal patch-clamp recordings. For AMPAR sEPSC recordings, CA1 pyramidal neurons were patch clamped using pipettes (4.0-6.0 $\mathrm{M} \Omega$ resistance), and a gap-free recording was performed for $10 \mathrm{~min}$ in ACSF as described previously (Fiacco and McCarthy, 2004). For NMDAR sEPSCs, neurons were voltage clamped at $-70 \mathrm{mV}$ and superfused with

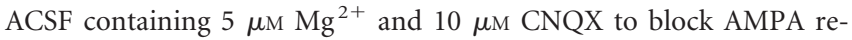
sponses. For the ambient glutamate recordings, neurons were patch clamped at a holding potential of $+40 \mathrm{mV}$ in normal ACSF with an internal solution containing the following (in $\mathrm{mm}$ ): 100 cesium methanesulfonate $\left(\mathrm{CH}_{3} \mathrm{CsO}_{3} \mathrm{~S}\right), 10$ tetraethylammonium- $\mathrm{Cl}, 4 \mathrm{NaCl}, 1 \mathrm{MgCl}_{2}, 10$ HEPES, 10 BAPTA, 5 phosphocreatine, 2 ATP, 0.3 GTP, pH adjusted to 7.3 with $\mathrm{CsOH}$. Ambient glutamate current was recorded in ACSF containing $1 \mu \mathrm{M}$ tetrodotoxin (TTX) and $100 \mu \mathrm{M}$ picrotoxin.

Data collection and analysis. Membrane currents were recorded using an Axopatch 200B amplifier (Molecular Devices, Sunnyvale, CA). Traces were analyzed for sEPSCs in Clampfit 10.2 software (Molecular Devices) using a template constructed from four to six sEPSCs intrinsic to each recording. The event statistics were taken for each individual event and then averaged. The averaged event statistics from each cell were then averaged together and reported as mean \pm SEM. For tonic NMDA currents from ambient glutamate recordings, membrane currents were normalized to the amplitude of the currents blocked by a saturating concentration of D-AP-5. Statistical differences between two samples were evaluated using Student's $t$ test performed using Prism 4 software (Graphpad, San Diego, CA).

Histology. Littermate control and $\mathrm{IP}_{3} \mathrm{R} 2 \mathrm{KO}$ brains were fixed with formalin and embedded sagittally in paraffin. Brains were sectioned at 6 $\mu \mathrm{m}$ thickness with a Leica (Nussloch, Germany) microtome from P30 littermate controls and IP ${ }_{3} \mathrm{R} 2 \mathrm{KOs}$. Sections were stained with hematoxylin and eosin and imaged using a Zeiss (Oberkochen, Germany) Axioscope light microscope.

Reagents. D-AP-5, TTX, CNQX, (RS)-3,5-dihydroxyphenylglycine (DHPG), histamine, carbachol, thapsigargin, DL-threo- $\beta$-benzyloxyaspartic acid (DL-TBOA), and picrotoxin were obtained from Tocris Bioscience (Bristol, UK). Calcium Green-1 A.M., Fluo-4, Fluo-4 A.M., and Alexa 568 were obtained from Invitrogen (Carlsbad, CA).

\section{Results}

\section{Histological analysis of $\mathrm{IP}_{3} \mathrm{R} 2 \mathrm{KO}$ mouse brains}

It has been reported previously that mice homozygous for the $\mathrm{IP}_{3} \mathrm{R} 2 \mathrm{KO}$ allele are viable and fertile and that the mice display no overt behavioral abnormalities (Li et al., 2005). We performed histological staining of paraffin-embedded sections from adult $\mathrm{IP}_{3} \mathrm{R} 2 \mathrm{KO}$ mice to determine whether there were any obvious abnormalities in brain cytoarchitecture indicative of improper proliferation or neurite outgrowth during development. Hematoxylin and eosin staining of P30 littermate control $(n=3)$ and $\mathrm{IP}_{3} \mathrm{R} 2 \mathrm{KO}(n=3)$ brains revealed that lack of $\mathrm{IP}_{3} \mathrm{R} 2$ does not significantly affect brain cytoarchitecture. The hippocampus, cortex, and cerebellum of $\mathrm{IP}_{3} \mathrm{R} 2 \mathrm{KO}$ mice were examined and did not show any obvious structural abnormalities (Fig. $1 A$ ). These findings suggest that $\mathrm{IP}_{3} \mathrm{R} 2$-mediated release of $\mathrm{Ca}^{2+}$ is not critical to the overall development of the brain or that alternate $\mathrm{IP}_{3} \mathrm{Rs}$ may be expressed in astrocytes during development.

\section{$\mathrm{IP}_{3} \mathrm{R} 2 \mathrm{KO}$ hippocampal astrocytes lack spontaneous and Gq- linked GPCR $\mathrm{Ca}^{2+}$ increases}

Astrocytes are known to respond to a wide variety of Gq GPCR agonists with $\mathrm{Ca}^{2+}$ elevations (Verkhratsky and Kettenmann, 1996). To address the functional role of $I_{3} R 2$ in hippocampal astrocytes, we performed $\mathrm{Ca}^{2+}$ imaging experiments on bulkloaded slices from littermate control and $\mathrm{IP}_{3} \mathrm{R} 2 \mathrm{KO}$ mice. Bath application of a $\mathrm{G}_{\mathrm{q}}$-linked GPCR agonist cocktail (DHPG, histamine, carbachol; $10 \mu \mathrm{M}$ each) to hippocampal slices taken from littermate controls elicited robust increases in astrocyte intracellular $\mathrm{Ca}^{2+}$ (65\% of 144 cells from 17 slices; five animals total) (Fig. $2 A, B$ ). In striking contrast, the GPCR cocktail failed to elicit $\mathrm{Ca}^{2+}$ increases in $\mathrm{IP}_{3} \mathrm{R} 2 \mathrm{KO}$ hippocampal astrocytes ( $0 \%$ of 104 cells from 11 slices; five animals total) (Fig. 2A,B). Similar results were obtained in experiments using $100 \mu \mathrm{M}$ ATP, with $80 \%$ of 40 astrocytes from littermate controls (four slices total from one 
Hippocampus
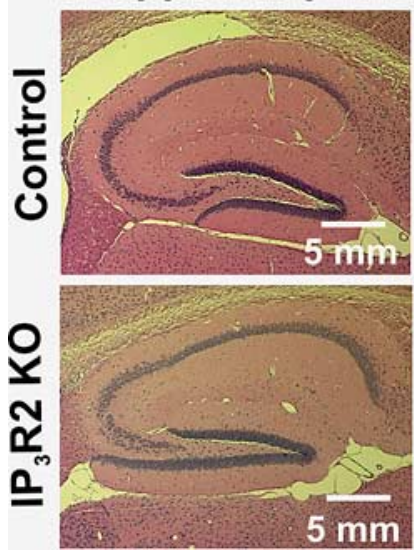

Cortex

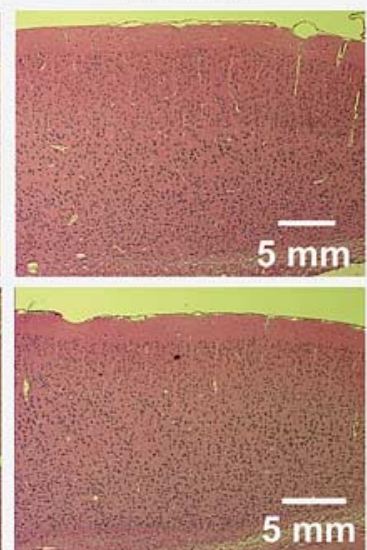

Cerebellum

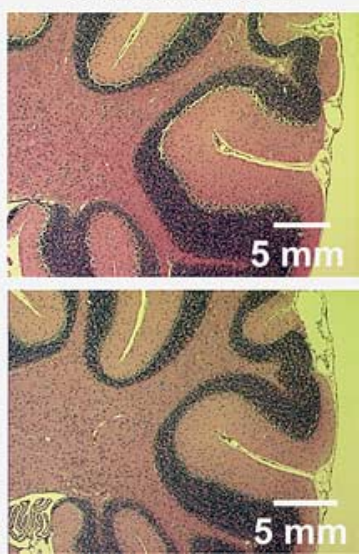

Figure 1. Histological analysis of $I_{3} R 2 \mathrm{KO}$ brains reveals no obvious abnormalities. Histological staining of brain sections were taken from littermate control $(n=3)$ and IP ${ }_{3} \mathrm{R} 2 \mathrm{KO}(n=3)$ mice. Six-micrometer-thick paraffin-embedded sections were cut and stained with hematoxylin and eosin to visualize brain cytoarchitecture. No difference in the gross overall morphology or in the general cell layering was apparent between the $\mathbb{I}_{3} \mathrm{R} 2 \mathrm{KO}$ mice and littermate controls in any brain region; data from hippocampus, cortex, and cerebellum are shown.

animal) and $0 \%$ of 38 astrocytes from $\mathrm{IP}_{3} \mathrm{R} 2 \mathrm{KOs}$ (three slices total from one animal) responding with $\mathrm{Ca}^{2+}$ increases (Fig. $2 A, B)$. In experiments where thapsigargin $(2 \mu \mathrm{M})$ was applied as a control for $\mathrm{Ca}^{2+}$ increases, both littermate control $(45 \%$ of 40 cells; four slices total from one mouse) and $\mathrm{IP}_{3} \mathrm{R} 2 \mathrm{KO}$ ( $45 \%$ of 38 cells, three slices total from one mouse) astrocytes responded to thapsigargin with increases in intracellular $\mathrm{Ca}^{2+}$, indicating that the $\mathrm{Ca}^{2+}$ stores themselves were intact (Fig. 2A,B).

Astrocytes have also been reported to exhibit spontaneous $\mathrm{Ca}^{2+}$ oscillations in the absence of neuronal activity (Nett et al., 2002). To determine whether $I_{3} R 2$ is necessary for spontaneous $\mathrm{Ca}^{2+}$ oscillations, $\mathrm{Ca}^{2+}$ measurements were analyzed in astrocytes in the absence of agonist application. In bulk-loaded slices from littermate controls, spontaneous $\mathrm{Ca}^{2+}$ increases were observed in $21 \%$ of 144 total astrocytes ( 17 slices from five animals) but were absent in $\mathrm{IP}_{3} \mathrm{R} 2 \mathrm{KO}$ astrocytes ( $0 \%$ of 104 total cells, 11 slices from five animals). Together, these data indicate that astrocytes lacking $\mathrm{IP}_{3} \mathrm{R} 2$ are incapable of releasing $\mathrm{Ca}^{2+}$ from internal stores either spontaneously or in response to agonists to $\mathrm{G}_{\mathrm{q}^{-}}$ linked GPCRs.

\section{Neuronal $\mathrm{Ca}^{2+}$ increases are intact in $\mathrm{IP}_{3} \mathrm{R} 2 \mathrm{KO} \mathrm{CA} 1$ pyramidal neurons}

To address the question of a potential functional role of $\mathrm{IP}_{3} \mathrm{R} 2$ in hippocampal neurons, we conducted $\mathrm{Ca}^{2+}$ imaging experiments on CA1 pyramidal neurons loaded with $\mathrm{Ca}^{2+}$ indicator via a patch pipette. Application of a $\mathrm{G}_{\mathrm{q}}$-linked GPCR agonist cocktail (in $\mu \mathrm{M}$ : $50 \mathrm{DHPG}, 10$ histamine, 10 carbachol) in $1 \mu \mathrm{M}$ TTX to block action potentials elicited $\mathrm{Ca}^{2+}$ transients in $\mathrm{IP}_{3} \mathrm{R} 2 \mathrm{KO}$ neurons ( different in amplitude (Fig. $2 D$, left) $(p=0.39)$ or duration (Fig. $2 D$, right $)(p=0.08)$ from those measured in littermate controls (eight cells from eight slices, five animals total). These results indicate that lack of $\mathrm{IP}_{3} \mathrm{R} 2$ does not significantly alter $\mathrm{IP}_{3} \mathrm{R}$ dependent $\mathrm{Ca}^{2+}$ signaling in CA1 pyramidal neurons.

\section{Lack of spontaneous $\mathrm{Ca}^{2+}$ oscillations in astrocytes does not} affect CA1 pyramidal neuron sEPSCs

It has been reported that spontaneous and evoked astrocyte $\mathrm{Ca}^{2+}$ elevations lead to gliotransmitter release, which modulates basal neuronal excitatory and inhibitory synaptic activity via the activation of neuronal mGluRs and iGluRs (Hassinger et al., 1995; Araque et al., 1998b; Kang et al., 1998; Parri et al., 2001; Fiacco and McCarthy, 2004; Liu et al., 2004a,b). The effect of blocking astrocyte $\mathrm{Ca}^{2+}$ elevations and therefore $\mathrm{Ca}^{2+}$ dependent gliotransmitter release on basal neuronal excitatory activity has not been addressed thoroughly. Therefore, we performed whole-cell patch-clamp experiments on CA1 pyramidal neurons and found that basic neuronal properties such as resting membrane potential (control, $-61.7 \pm 1.1 \mathrm{mV} ; \mathrm{IP}_{3} \mathrm{R} 2 \mathrm{KO},-60.3 \pm 0.8$ $\mathrm{mV} ; p=0.33$ ), membrane resistance (control, $274.5 \pm 26.2 \mathrm{M} \mathrm{IP}_{3} \mathrm{R} 2 \mathrm{KO}, 249.1 \pm$ $15.5 \mathrm{MÜ} ; p=0.40)$, and membrane capacitance (control, $89.6 \pm 5.5 \mathrm{pF} ; \mathrm{IP}_{3} \mathrm{R} 2 \mathrm{KO}$, $96.4 \pm 4.8 \mathrm{pF} ; p=0.36)$ were not significantly different between littermate control and $\mathrm{IP}_{3} \mathrm{R} 2 \mathrm{KO}$ neurons (control, 21 cells from 20 slices, 10 animals total; $\mathrm{IP}_{3} \mathrm{R} 2 \mathrm{KO}$, 22 cells from 17 slices, 10 animals total). In addition, there were no significant differences found between littermate control and $\mathrm{IP}_{3} \mathrm{R} 2 \mathrm{KO}$ AMPAR sEPSC peak amplitude $(p=0.62), 10-90 \%$ rise time $(p=0.94)$, decay tau $(p=0.66)$, and event frequency $(p=0.90)$ (Fig. $3 B)$ (control, 15 cells from 14 slices, nine animals total; $\mathrm{IP}_{3} \mathrm{R} 2 \mathrm{KO}, 16$ cells from 11 slices, nine animals total). Additionally, no significant differences were found in NMDARmediated sEPSCs in peak amplitude $(p=0.39), 10-90 \%$ rise time $(p=0.92)$, decay tau $(p=0.94)$, and event frequency $(p=$ 0.70 ) (Fig. 3D) (control, 15 cells from 13 slices, six animals total; $\mathrm{IP}_{3} \mathrm{R} 2 \mathrm{KO}$, nine cells from eight slices, three animals total). Together, these results indicate that lack of $\mathrm{IP}_{3} \mathrm{R}$-dependent $\mathrm{Ca}^{2+}$ increases in astrocytes has no significant effect on either spontaneous AMPAR- or NMDAR-mediated excitatory synaptic currents in CA1 pyramidal neurons.

\section{Ambient glutamate of astrocyte origin is not released in a $\mathrm{Ca}^{2+}$-dependent manner}

Ambient glutamate levels in the hippocampus have been the focus of several recent studies (Herman and Jahr, 2007; Le Meur et al., 2007). Findings in this area suggest that the majority of ambient glutamate present in the hippocampus is of glial origin and might be released in a $\mathrm{Ca}^{2+}$-independent manner (Jabaudon et al., 1999; Cavelier and Attwell, 2005). To address whether ambient glutamate release occurs in a $\mathrm{Ca}^{2+}$-independent manner, whole-cell currents were recorded from CA1 pyramidal neurons held at $+40 \mathrm{mV}$ in ACSF containing $1 \mu \mathrm{M}$ TTX and $100 \mu \mathrm{M}$ picrotoxin to isolate NMDAR-mediated currents. Similar to previous reports (Herman and Jahr, 2007; Le Meur et al., 2007), application of the NMDAR antagonist D-AP-5 $(50 \mu \mathrm{M})$ revealed a tonic NMDAR current of $33.7 \pm 6.0 \mathrm{pA}$ in littermate control neurons ( six cells from six slices, four animals total) (Fig. 4A,B). Recordings done in $\mathrm{IP}_{3} \mathrm{R} 2 \mathrm{KO}$ neurons found a D-AP-5-sensitive current that was not significantly different from that found in littermate control neurons ( $35.7 \pm 9.2 \mathrm{pA} ; p=0.8$; five cells from five slices, three animals total) (Fig. $4 A, B$ ).

To determine whether removal of astrocytic $\mathrm{Ca}^{2+}$ increases affects ambient glutamate accumulation during elevated extracellular glutamate, glutamate transporters were blocked using $100 \mu \mathrm{M}$ TBOA. Application of TBOA caused a $7.0 \pm 1.3$-fold 
change in the tonic NMDAR current of littermate control neurons ( six cells from six slices, four animals total) and a similar fold change in $\mathrm{KO}$ neurons of $8.6 \pm 1.1$ (five cells from five slices, three animals total; $p=0.4$ ) (Fig. 4C,D). Additionally, there was no significant difference in the level of synaptic noise during TBOA application in the $\mathrm{IP}_{3} \mathrm{R} 2$ KOs (55.4 $\pm 4.1 \mathrm{pA}$; six cells from six animals; four slices total) versus littermate controls $(66.8 \pm 5.4 \mathrm{pA} ; p=0.14$; five cells from five slices; three animals total). Overall, these data indicate that astrocyte $\mathrm{Ca}^{2+}$ elevations do not play a significant role in regulating the ambient extracellular concentration of glutamate.

\section{Discussion}

Astrocytes have been reported to display both spontaneous and evoked intracellular $\mathrm{Ca}^{2+}$ increases using a variety of stimulation protocols (Montana et al., 2006). Astrocyte $\mathrm{Ca}^{2+}$ increases are caused by the release of $\mathrm{Ca}^{2+}$ from internal stores after activation of $\mathrm{IP}_{3} \mathrm{Rs}$ (Sheppard et al., 1997; Scemes, 2000). In this communication, we show that knock-out of $\mathrm{IP}_{3} \mathrm{R} 2$ abolishes both spontaneous and $\mathrm{G}_{\mathrm{q}}$-linked GPCR agonist evoked $\mathrm{IP}_{3} \mathrm{R}$-dependent $\mathrm{Ca}^{2+}$ increases in astrocytes. To our knowledge, the findings presented here are the first demonstration that astrocyte $\mathrm{Ca}^{2+}$ release in situ is functionally reliant on $\mathrm{IP}_{3} \mathrm{R} 2$. In contrast, $\mathrm{IP}_{3} \mathrm{R}$ dependent $\mathrm{Ca}^{2+}$ increases in CA1 pyramidal neurons remain intact, indicating that $\mathrm{IP}_{3} \mathrm{R} 2$ is not necessary for neuronal $\mathrm{IP}_{3} \mathrm{R}$ mediated $\mathrm{Ca}^{2+}$ increases, or that $\mathrm{IP}_{3} \mathrm{R} 2$ may not be expressed by CA1 pyramidal neurons. This is supported by immunostaining data showing that $\mathrm{IP}_{3} \mathrm{R} 2$ is not expressed in neurons (Sharp et al., 1999; Hertle and Yeckel, 2007). It is somewhat surprising that in astrocytes, in which $\mathrm{IP}_{3} \mathrm{R}$-dependent intracellular $\mathrm{Ca}^{2+}$ signals are thought to modulate an increasingly large number of key processes in brain (neuronal excitability, synaptic plasticity, and cerebrovascular control), that deletion of $\mathrm{IP}_{3} \mathrm{R} 2$ should result in the complete loss of $\mathrm{Ca}^{2+}$ activity without any apparent form of compensation. It is even more surprising that these mice: (1) are not embryonic lethal, (2) do not show early mortality, and (3) do not exhibit any obvious histological or behavioral abnormalities. They appear healthy, breed well, and live normal lifespans. This is in stark contrast to the $\mathrm{IP}_{3} \mathrm{R} 1 \mathrm{KO}$ mouse model, which displays tonic-clonic seizures, ataxia, and either die in utero or by weaning age (P21)

(Matsumoto et al., 1996). Additional behavioral testing of the $\mathrm{IP}_{3} \mathrm{R} 2 \mathrm{KO}$ mouse model will provide valuable insight into the role of astrocyte $\mathrm{Ca}^{2+}$-dependent signaling in specific animal behaviors such as learning and memory.

A SEM.

\section{Control}

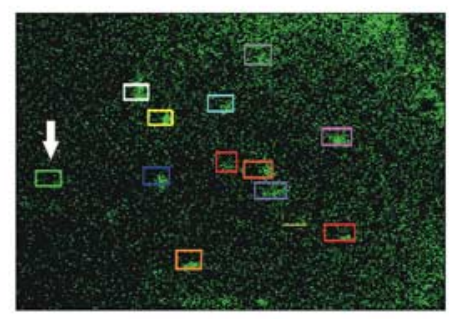

$\mathrm{IP}_{3} \mathrm{R} 2 \mathrm{KO}$

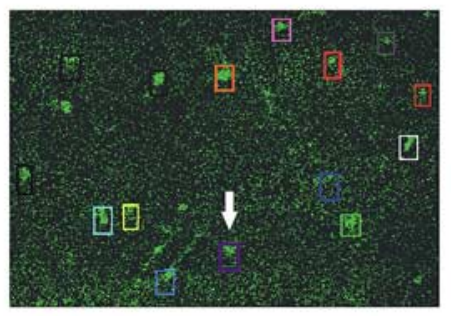

$\begin{array}{llll}\text { ATP } & \text { Ct } & \text { Tg } \\ \Downarrow & \downarrow & \downarrow & \downarrow\end{array}$

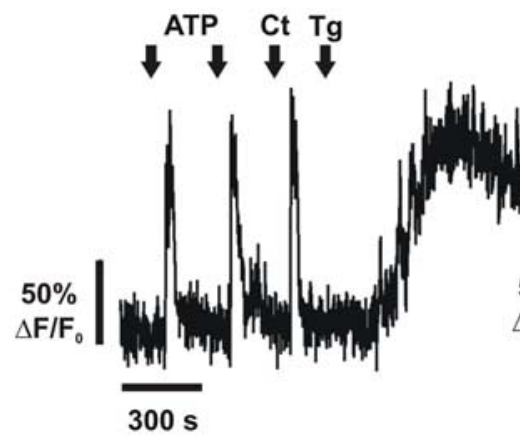

B
Control

$80.0 \%$ (32/40 cells)

$65.0 \%(93 / 144$ cells $)$

$45.0 \%$ (18/40cells) $\underline{\text { IP }} \underline{3}$ R2 KO

$0 \%$ (0/38 cells)

$0 \%(0 / 104$ cells $)$

$45.0 \%(17 / 38$ cells $)$
Thapsigargin $(\mathrm{Tg})$

C

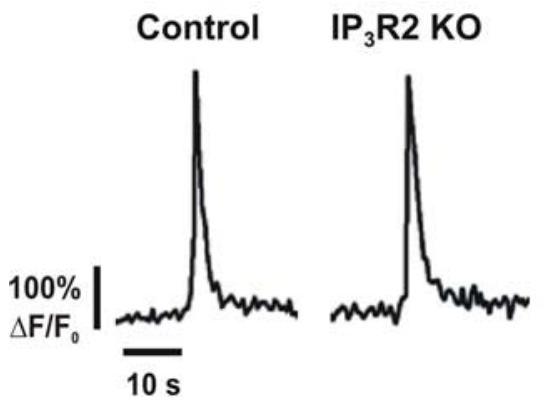

D $\quad \mathrm{IP}_{3} \mathrm{R}$-mediated $\mathrm{Ca}^{2+}$ increases

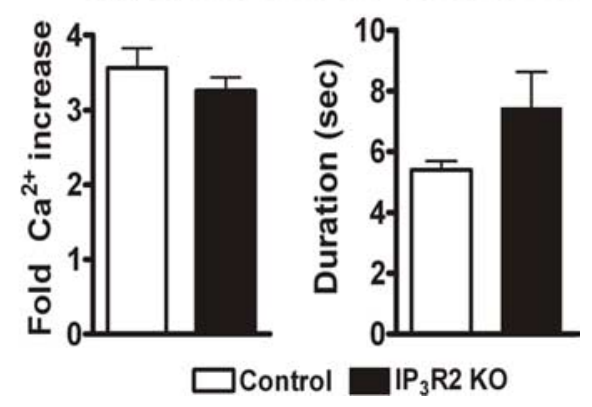

Figure 2. Knock-out of $\mathrm{IP}_{3} \mathrm{R} 2$ affects astrocyte but not neuronal GPCR-mediated $\mathrm{Ca}^{2+}$ increases. $\boldsymbol{A}$, Representative $\mathrm{Ca}^{2+}$ traces from astrocytes of Calcium Green AM-loaded hippocampal slices. Regions of interest were placed over the cell bodies of bulk-loaded hippocampal astrocytes to measure $\mathrm{Ca}^{2+}$ increases in response to agonist application (top). Application of ATP $(100 \mu \mathrm{m})$ or a $\mathrm{G}_{\mathrm{q}}$-linked GPCR agonist cocktail (Ct, $10 \mu \mathrm{M}$ DHPG, $10 \mu \mathrm{m}$ histamine, and $10 \mu \mathrm{m}$ carbachol) elicited $\mathrm{Ca}^{2+}$ responses in astrocytes from littermate control but not $\mathrm{IP}_{3} \mathrm{R} 2 \mathrm{KO}$ hippocampal slices. The arrows indicate the astrocyte $\mathrm{Ca}^{2+}$ traces shown in the bottom panels. Thapsigargin $\left(\mathrm{Tg} ; 2 \mu \mathrm{m}\right.$ ) was used as a control and increased $\mathrm{Ca}^{2+}$ in astrocytes of both littermate control and IP $\mathrm{P}_{3} \mathrm{~K} \mathrm{KO}$ s. Data are presented as fold increases over baseline. $\boldsymbol{B}$, Percentage of astrocytes responding to application of ATP or the $\mathrm{G}_{\mathrm{q}}$-linked GPCR agonist cocktail from all experiments. C, Representative $\mathrm{Ca}^{2+}$ traces from CA1 pyramidal neurons patch clamped with internal solution containing Fluo-4 $\mathrm{Ca}^{2+}$ indicator in response to application of a $\mathrm{G}_{\mathrm{q}}$-linked GPCR cocktail (50 $\mu \mathrm{M}$ DHPG, $10 \mu \mathrm{m}$ histamine, $10 \mu \mathrm{m}$ carbachol) in the presence of $1 \mu \mathrm{M}$ TTX to block action potentials. $\boldsymbol{D}$, Amplitude and duration of $\mathrm{IP}_{3} \mathrm{R}$-mediated $\mathrm{Ca}^{2+}$ responses in CA1 pyramidal neurons (control, $n=8 ; \mathrm{IP}_{3} \mathrm{R} 2 \mathrm{KO}$, $n=6$ ). There were no significant differences for amplitude (left; $p=0.39$ ) or duration (right; $p=0.08$ ). Error bars indicate

Astrocytes have been implicated as a major source of ambient glutamate in the hippocampus (Jabaudon et al., 1999; Cavelier and Attwell, 2005; Herman and Jahr, 2007; Le Meur et al., 2007). In the present study, removal of astrocyte $\mathrm{Ca}^{2+}$ increases has no 


\section{A
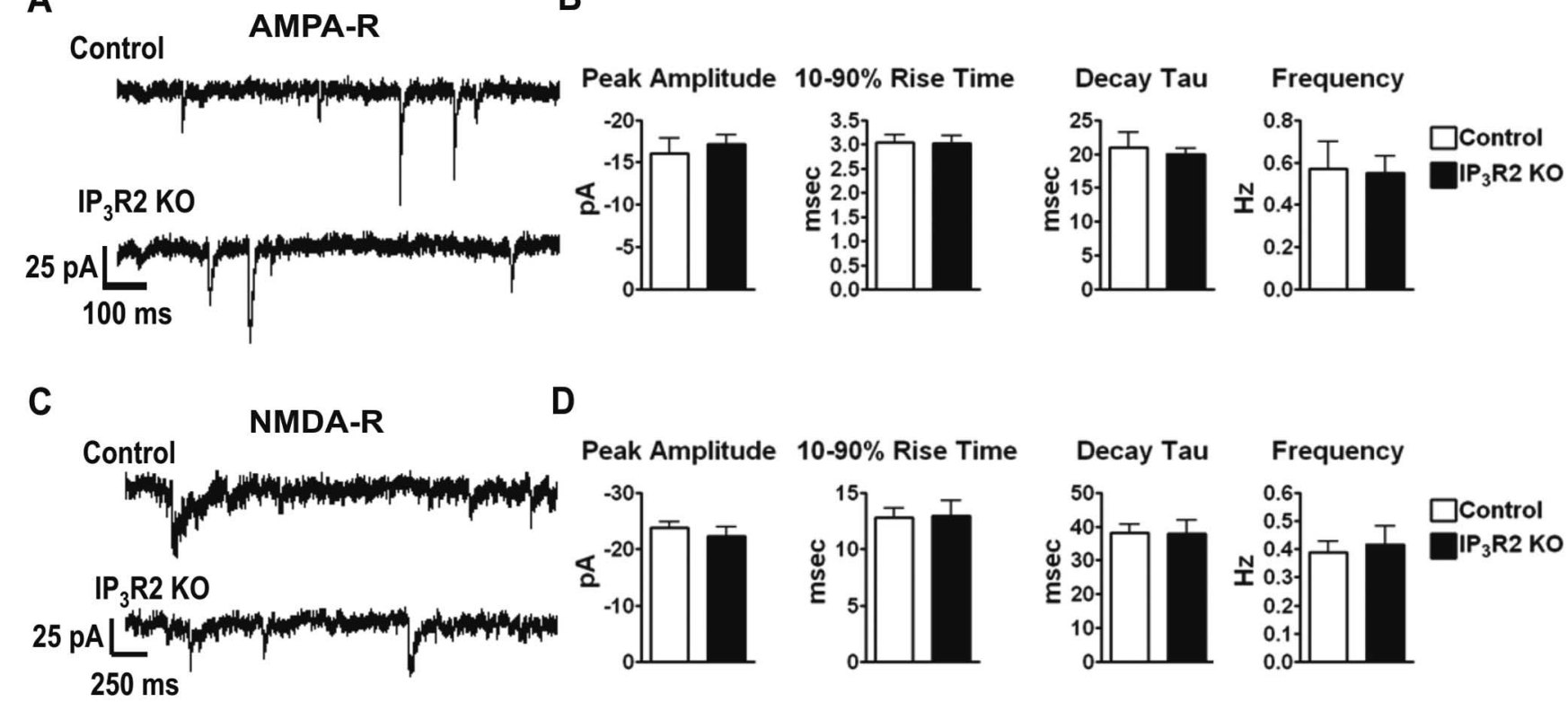

D
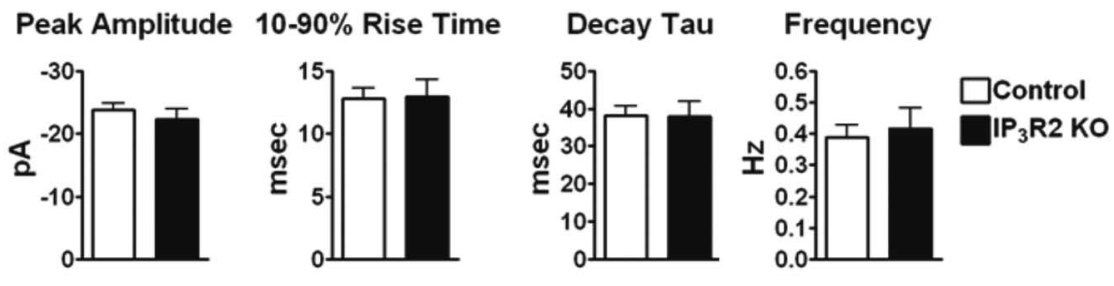

Figure 3. Spontaneous EPSCs from CA1 pyramidal neurons are unchanged in IP ${ }_{3} R 2$ KO mice. $A$, Representative AMPAR sEPSC traces from littermate control $(n=15)$ and IP $R 2$ KO $(n=16) C A 1$ pyramidal neurons. $\boldsymbol{B}$, AMPARSEPS ( peak amplitude $(p=0.62), 10-90 \%$ rise times $(p=0.94)$, decay tau $(p=0.66)$, and event frequency $(p=0.90)$ were not significantly different between littermate control and IP $P_{3} 2 \mathrm{~K} 0$ CA1 pyramidal neurons as determined by Student'st test. C, Representative NMDARsEPSC traces from littermate control $(n=15)$ and IP ${ }_{3} \mathrm{R} 2 \mathrm{KO}(n=9) \mathrm{CA} 1$ pyramidal neurons. $\boldsymbol{D}$, NMDAR sEPSC peak amplitude ( $p=0.39), 10-90 \%$ rise times $(p=0.92)$, decay tau ( $p=0.94)$, and event frequency $(p=0.70)$ were not significantly different between littermate control and $\mathrm{IP}_{3} \mathrm{R} 2 \mathrm{KO}$ CA1 pyramidal neurons as determined by Student's $t$ test. Error bars indicate SEM.

effect on the amplitude of the tonic NMDA-R mediated current activated by ambient glutamate. Furthermore, use of TBOA to block glutamate transporters revealed that the extent to which ambient glutamate accumulates during transporter block is unaffected by removal of $\mathrm{IP}_{3} \mathrm{R} 2$ in astrocytes (Fig. $4 \mathrm{~B}$ ). These findings are in agreement with the hypothesis that ambient glutamate release from astrocytes occurs in a $\mathrm{Ca}^{2+}$-independent manner, possibly through nonvesicular release mechanisms such as connexin hemichannels, P2X channels or anion channels (Cavelier and Attwell, 2005; Malarkey and Parpura, 2008).

A substantial literature has developed in the field of astrocyte biology concerning the role of $\mathrm{Ca}^{2+}$-dependent release of gliotransmitters such as ATP (which is converted to adenosine by ectonucleotidases) and glutamate on neuronal activity (for review, see Carmignoto and Fellin, 2006; Fellin et al., 2006b; Fiacco and McCarthy, 2006). These findings led to the development of the tripartite synapse model, in which astrocytes are active participants in synaptic transmission through $\mathrm{Ca}^{2+}$-dependent gliotransmitter release (Araque et al., 1999). Although the majority of studies have focused on the outcome of pharmacologically evoking astrocyte $\mathrm{Ca}^{2+}$, very few studies have directly described the effect of blocking $\mathrm{IP}_{3} \mathrm{R}$-dependent $\mathrm{Ca}^{2+}$ release on basal excitatory neuronal activity. Furthermore, it has been reported that spontaneous $\mathrm{Ca}^{2+}$ increases and subsequent glutamate release from astrocytes directly evoke NMDAR-mediated currents in neurons (Parri et al., 2001). Additionally, astrocyte $\mathrm{Ca}^{2+}$ increases have been associated with neuronal $\mathrm{Ca}^{2+}$ increases mediated by iGluRs (Hassinger et al., 1995; Pasti et al., 2001; Fellin et al., 2004). A mathematical model incorporating data from numerous studies, including our own (Fiacco and McCarthy, 2004), on the role of astrocytes at the tripartite synapse predicts that astrocytes enhance synaptic release (Nadkarni and Jung, 2007). This is reflected by an increase in spontaneous postsynaptic events during and immediately after astrocyte $\mathrm{Ca}^{2+}$ elevations that trigger astrocytic release of glutamate compared with syn- apses lacking an associated astrocyte (Nadkarni and Jung, 2007). According to this model, a lack of astrocyte $\mathrm{Ca}^{2+}$ increases would produce a reduced event frequency, reflecting reduced synaptic release. It has also been reported that heterosynaptic depression caused by $\mathrm{Ca}^{2+}$-dependent ATP release from astrocytes suppresses glutamate release at CA3-CA1 synapses (Pascual et al., 2005). Based on these findings, it is reasonable to speculate that abolishment of $\mathrm{Ca}^{2+}$ increases in $\mathrm{IP}_{3} \mathrm{R} 2 \mathrm{KO}$ astrocytes would lead to significant changes in basal excitatory neuronal activity and perhaps long-term changes in brain activity and behavior. In recordings of sEPSCs from $\mathrm{IP}_{3} \mathrm{R} 2 \mathrm{KO}$ and littermate control CA1 pyramidal neurons, we found no significant differences in peak amplitude, 10-90\% rise time, and decay tau of both AMPARand NMDAR-mediated synaptic currents. Furthermore, we found no change in the frequency of AMPAR- and NMDARmediated sEPSCs, suggesting that lack of $\mathrm{Ca}^{2+}$ increases and $\mathrm{Ca}^{2+}$-dependent gliotransmitter release may not significantly affect baseline release probability from neuronal synaptic terminals.

The IP ${ }_{3} \mathrm{R} 2 \mathrm{KO}$ mouse model offers a compliment to another mouse model developed in our laboratory that enables selective stimulation of $\mathrm{G}_{\mathrm{q}}$-GPCR signaling cascades in astrocytes (Fiacco et al., 2007). The findings presented here support our recent discovery using the MrgAl transgenic mice that selective, widespread astrocyte $\mathrm{Ca}^{2+}$ elevations have no effect on baseline neuronal excitatory synaptic activity. It has been reported previously by a number of labs (including our own) that mechanical stimulation or uncaging $\mathrm{Ca}^{2+}$ or $\mathrm{IP}_{3}$ in astrocytes leads to gliotransmitter release and changes in neuronal excitatory activity (Parpura and Haydon, 2000; Fiacco and McCarthy, 2004), neuronal inhibitory activity (Kang et al., 1998; Liu et al., 2004a,b), and cerebrovascular tone (Zonta et al., 2003; Straub et al., 2006). Although use of these pharmacological tools may elicit such responses, they may represent a nonphysiological level of stimulation that does not occur in vivo and therefore does not accurately 
recapitulate endogenous $\mathrm{IP}_{3}$ generating signaling pathways. There may be important regulatory mechanisms activated in GPCR signaling that work downstream of $\mathrm{Ca}^{2+}$ to inhibit vesicular release of glutamate by astrocytes. The $\mathrm{IP}_{3} \mathrm{R} 2 \mathrm{KO}$ and MrgA1 mouse models together fully corroborate the concept that stimulation of astrocytic $\mathrm{G}_{\mathrm{q}}$ GPCRs and spontaneous astrocyte $\mathrm{Ca}^{2+}$ activity are not sufficient to cause vesicular release of glutamate from astrocytes, and that astrocyte $\mathrm{Ca}^{2+}$ elevations are not necessary for normal neuronal excitatory synaptic activity in hippocampal CA1 pyramidal neurons.

The $\mathrm{IP}_{3} \mathrm{R} 2$ mouse model also affords significant improvement over previously used techniques to examine the necessity of evoked $\mathrm{IP}_{3} \mathrm{R}$-dependent $\mathrm{Ca}^{2+}$ increases to changes in neuronal synaptic activity. Calcium chelators such as BAPTA or the bulk loadable BAPTA-AM have been used to block astrocyte $\mathrm{Ca}^{2+}$ increases. There are technical issues with the use of BAPTA and $\mathrm{Ca}^{2+}$ chelators that are eliminated by the use of the $\mathrm{IP}_{3} \mathrm{R} 2 \mathrm{KO}$ mouse model. In the $\mathrm{IP}_{3} \mathrm{R} 2 \mathrm{KO}$, release of $\mathrm{Ca}^{2+}$ from astrocyte internal stores is removed specifically, without causing a global change in the resting cytoplasmic $\mathrm{Ca}^{2+}$ concentration.

In conclusion, the $\mathrm{IP}_{3} \mathrm{R} 2 \mathrm{KO}$ mouse model represents a significant step forward in our ability to study the astrocyte $\mathrm{Ca}^{2+}$ contribution to key physiological processes. Use of this model has the potential to clarify and further define the role of astrocytes in physiology and pathology without the use of pharmacological manipulations to block astrocyte $\mathrm{Ca}^{2+}$ increases. This model can be used to identify $\mathrm{Ca}^{2+}$ dependent and $\mathrm{Ca}^{2+}$-independent mechanisms and their influence on astrocyte-neuronal communication, as well as reevaluate the many important brain functions to which $\mathrm{Ca}^{2+}$ dependent gliotransmitter release has been reported to play a significant role.

\section{References}

Aguado F, Espinosa-Parrilla JF, Carmona MA, Soriano E (2002) Neuronal activity regulates correlated network properties of spontaneous calcium transients in astrocytes in situ. J Neurosci 22:9430-9444.

Andersson M, Blomstrand F, Hanse E (2007) Astrocytes play a critical role in transient heterosynaptic depression in the rat hippocampal CA1 region. J Physiol (Lond) 585:843-852.

Araque A, Parpura V, Sanzgiri RP, Haydon PG (1998a) Glutamatedependent astrocyte modulation of synaptic transmission between cultured hippocampal neurons. Eur J Neurosci 10:2129-2142.

Araque A, Sanzgiri RP, Parpura V, Haydon PG (1998b) Calcium elevation in astrocytes causes an NMDA receptor-dependent increase in the frequency of miniature synaptic currents in cultured hippocampal neurons. J Neurosci 18:6822-6829.

Araque A, Parpura V, Sanzgiri RP, Haydon PG (1999) Tripartite synapses: glia, the unacknowledged partner. Trends Neurosci 22:208-215.

Carmignoto G, Fellin T (2006) Glutamate release from astrocytes as a nonsynaptic mechanism for neuronal synchronization in the hippocampus. J Physiol (Paris) 99:98-102.

Cavelier P, Attwell D (2005) Tonic release of glutamate by a DIDS-sensitive mechanism in rat hippocampal slices. J Physiol (Lond) 564:397-410.

B

\section{Tonic NMDA-R Current}

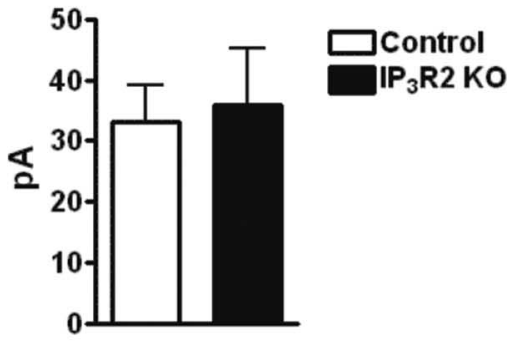

D

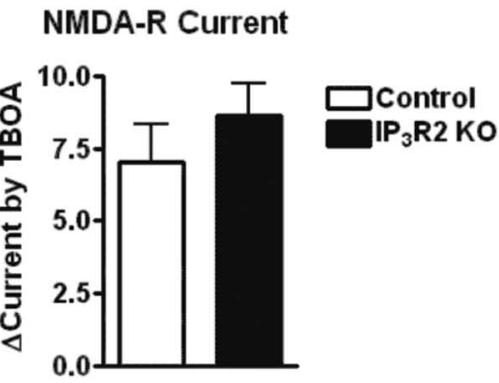


Hertle DN, Yeckel MF (2007) Distribution of inositol-1,4,5-trisphosphate receptor isotypes and ryanodine receptor isotypes during maturation of the rat hippocampus. Neuroscience 150:625-638.

Hirase H, Qian L, Bartho P, Buzsaki G (2004) Calcium dynamics of cortical astrocytic networks in vivo. PLoS Biol 2:E96.

Holtzclaw LA, Pandhit S, Bare DJ, Mignery GA, Russell JT (2002) Astrocytes in adult rat brain express type 2 inositol 1,4,5-trisphosphate receptors. Glia 39:69-84.

Jabaudon D, Shimamoto K, Yasuda-Kamatani Y, Scanziani M, Gahwiler BH, Gerber U (1999) Inhibition of uptake unmasks rapid extracellular turnover of glutamate of nonvesicular origin. Proc Natl Acad Sci USA 96:8733-8738.

Jensen AM, Chiu SY (1990) Fluorescence measurement of changes in intracellular calcium induced by excitatory amino acids in cultured cortical astrocytes. J Neurosci 10:1165-1175.

Kang J, Jiang L, Goldman SA, Nedergaard M (1998) Astrocyte-mediated potentiation of inhibitory synaptic transmission. Nat Neurosci 1:683-692.

Kang N, Xu J, Xu Q, Nedergaard M, Kang J (2005) Astrocytic glutamate release-induced transient depolarization and epileptiform discharges in hippocampal CA1 pyramidal neurons. J Neurophysiol 94:4121-4130.

Le Meur K, Galante M, Angulo MC, Audinat E (2007) Tonic activation of NMDA receptors by ambient glutamate of non-synaptic origin in the rat hippocampus. J Physiol (Lond) 580:373-383.

Li X, Zima AV, Sheikh F, Blatter LA, Chen J (2005) Endothelin-1-induced arrhythmogenic $\mathrm{Ca} 2+$ signaling is abolished in atrial myocytes of inositol-1,4,5-trisphosphate(IP3)-receptor type 2-deficient mice. Circ Res 96:1274-1281.

Liu QS, Xu Q, Kang J, Nedergaard M (2004a) Astrocyte activation of presynaptic metabotropic glutamate receptors modulates hippocampal inhibitory synaptic transmission. Neuron Glia Biol 1:307-316.

Liu QS, Xu Q, Arcuino G, Kang J, Nedergaard M (2004b) Astrocytemediated activation of neuronal kainate receptors. Proc Natl Acad Sci USA 101:3172-3177.

Malarkey EB, Parpura V (2008) Mechanisms of glutamate release from astrocytes. Neurochem Int 52:142-154.

Matsumoto M, Nakagawa T, Inoue T, Nagata E, Tanaka K, Takano H, Minowa O, Kuno J, Sakakibara S, Yamada M, Yoneshima H, Miyawaki A, Fukuuchi Y, Furuichi T, Okano H, Mikoshiba K, Noda T (1996) Ataxia and epileptic seizures in mice lacking type 1 inositol 1,4,5-trisphosphate receptor. Nature 379:168-171.

Montana V, Malarkey EB, Verderio C, Matteoli M, Parpura V (2006) Vesicular transmitter release from astrocytes. Glia 54:700-715.

Nadkarni S, Jung P (2007) Modeling synaptic transmission of the tripartite synapse. Phys Biol 4:1-9.

Nett WJ, Oloff SH, McCarthy KD (2002) Hippocampal astrocytes in situ exhibit calcium oscillations that occur independent of neuronal activity. J Neurophysiol 87:528-537.

Parpura V, Haydon PG (2000) Physiological astrocytic calcium levels stim- ulate glutamate release to modulate adjacent neurons. Proc Natl Acad Sci USA 97:8629-8634.

Parri HR, Gould TM, Crunelli V (2001) Spontaneous astrocytic Ca2+ oscillations in situ drive NMDAR-mediated neuronal excitation. Nat Neurosci 4:803-812.

Pascual O, Casper KB, Kubera C, Zhang J, Revilla-Sanchez R, Sul JY, Takano H, Moss SJ, McCarthy K, Haydon PG (2005) Astrocytic purinergic signaling coordinates synaptic networks. Science 310:113-116.

Pasti L, Zonta M, Pozzan T, Vicini S, Carmignoto G (2001) Cytosolic calcium oscillations in astrocytes may regulate exocytotic release of glutamate. J Neurosci 21:477-484.

Perea G, Araque A (2005) Properties of synaptically evoked astrocyte calcium signal reveal synaptic information processing by astrocytes. J Neurosci 25:2192-2203.

Porter JT, McCarthy KD (1996) Hippocampal astrocytes in situ respond to glutamate released from synaptic terminals. J Neurosci 16:5073-5081.

Scemes E (2000) Components of astrocytic intercellular calcium signaling. Mol Neurobiol 22:167-179.

Scemes E, Giaume C (2006) Astrocyte calcium waves: what they are and what they do. Glia 54:716-725.

Serrano A, Haddjeri N, Lacaille JC, Robitaille R (2006) GABAergic network activation of glial cells underlies hippocampal heterosynaptic depression. J Neurosci 26:5370-5382.

Sharp AH, Nucifora Jr FC, Blondel O, Sheppard CA, Zhang C, Snyder SH, Russell JT, Ryugo DK, Ross CA (1999) Differential cellular expression of isoforms of inositol 1,4,5-triphosphate receptors in neurons and glia in brain. J Comp Neurol 406:207-220.

Sheppard CA, Simpson PB, Sharp AH, Nucifora FC, Ross CA, Lange GD, Russell JT (1997) Comparison of type 2 inositol 1,4,5-trisphosphate receptor distribution and subcellular $\mathrm{Ca} 2+$ release sites that support $\mathrm{Ca} 2+$ waves in cultured astrocytes. J Neurochem 68:2317-2327.

Straub SV, Nelson MT (2007) Astrocytic calcium signaling: the information currency coupling neuronal activity to the cerebral microcirculation. Trends Cardiovasc Med 17:183-190.

Straub SV, Bonev AD, Wilkerson MK, Nelson MT (2006) Dynamic inositol trisphosphate-mediated calcium signals within astrocytic endfeet underlie vasodilation of cerebral arterioles. J Gen Physiol 128:659-669.

Tian GF, Azmi H, Takano T, Xu Q, Peng W, Lin J, Oberheim N, Lou N, Wang X, Zielke HR, Kang J, Nedergaard M (2005) An astrocytic basis of epilepsy. Nat Med 11:973-981.

Verkhratsky A, Kettenmann H (1996) Calcium signalling in glial cells. Trends Neurosci 19:346-352.

Weerth SH, Holtzclaw LA, Russell JT (2007) Signaling proteins in raft-like microdomains are essential for $\mathrm{Ca} 2+$ wave propagation in glial cells. Cell Calcium 41:155-167.

Zonta M, Angulo MC, Gobbo S, Rosengarten B, Hossmann KA, Pozzan T, Carmignoto G (2003) Neuron-to-astrocyte signaling is central to the dynamic control of brain microcirculation. Nat Neurosci 6:43-50. 